\title{
"Specific" scale compared with "generic" scale: a double measurement of the quality of life in a French community sample of obese subjects
}

\author{
Claude Le Pen, Emile Lévy, Frédéric Loos, Marie Noelle Banzet, Arnaud Basdevant
}

\begin{abstract}
Study objective-To determine the aspects of quality of life that are affected by weight in the general population, to develop a specific questionnaire (OSQOL) that can measure with reliability and validity the impact of overweight and obesity on well being, and to compare the results with those obtained using a well known generic tool (the "SF 36" scale).
\end{abstract}

Design-Cross sectional survey with matched control group.

Setting-Community.

Patients-A permanent survey base of approximately 10000 representative ordinary households were screened for weight and height. Five hundred subjects were randomly drawn from the sub-sample of adult people with a body mass index equal or greater than 27. A control sample of 500 subjects matched for sex, age, and employment status was drawn from the nonobese population.

Main results-A short specific Quality Of Life scale, the OSQOL, was produced that comprises 11 items belonging to four independent dimensions. Using this scale and the SF36, it was found that: (1) moderately obese subjects $(27 \leqslant \mathrm{BMI}<30)$ did not significantly differ from the control group except for physical capacity; (2) in the group of obese subjects with a BMI $>30$, quality of life seemed to be impaired for five of nine dimensions of the SF36 compared with the control population, all related to physical consequences of obesity. This population essentially perceived itself in terms of poor general health. (3) No significant difference was observed between the samples for the psychological and social dimensions of the SF36.

Conclusion-The quality of life of patients with severe obesity is impaired, but it mainly affects the physical consequences of the disease. The psychological and social repercussions that could have been expected to affect this population were not demonstrated. The hypothesis of a process of adaptation of the person and their social environment cannot therefore be excluded. Methodologically, comparison of the specific OSQOL with the generic SF3 shows clearly that the two kinds of scales correspond to different objectives and should be considered as complementary. ( $F$ Epidemiol Community Health 1998;52:445-450)
Excess weight and obesity have many effects in terms of public health. Several epidemiological studies have established the existence of a correlation between obesity and diseases such as diabetes, cardiovascular diseases, hypertension, etc.

Economic studies have also estimated the medical cost of obesity in a number of Western countries (USA, Sweden, the Netherlands, Australia, France) resulting in a figure of between $2 \%$ and $5 \%$ of total health expenditure. ${ }^{12}$

Paradoxically, little research has been conducted into the relation between obesity and quality of life. ${ }^{3}$ However, a reduction of the quality of life is probably one of the major personal consequences of obesity and constitutes one of the main reasons for seeking medical attention. $^{4}$

Evaluation of quality of life requires the use of a measuring instrument. Two types of instruments can generally be used: so called "specific" quality of life scales, specifically designed for a disease, in this case obesity; so called "generic" quality of life scales, used and validated across a broad range of chronic diseases.

The criteria for choosing between these two types of instruments are now well known. By definition, specific instruments are well adapted to the diseases for which they were designed and are therefore able to record even minor changes in quality of life. However, they are sometimes considered to be relatively tautological, providing results that are difficult to interpret because of the lack of an external reference. On the other side, generic scales may be poorly adapted to the particular conditions of a disease and lack sensitivity.

Apart from this debate, the question remains as to the relations between these two types of instruments, whether they are complementary or redundant and whether they provide coherent information.

The aim of this cross sectional study is to determine the aspects of quality of life that are affected by weight in the general population, to develop a specific questionnaire (OSQOL) that can measure with reliability and validity the impact of overweight and obesity on well being, and to compare the results with those obtained using a well known generic tool (the "SF 36" scale).

\section{Methods}

GENERAL APPROACH TO CONSTRUCTION OF THE SPECIFIC SCALE

The process of construction of the specific scale was based on the methodology generally used in this field. ${ }^{5}{ }^{6}$ This procedure consisted of 
Table 1 Study populations

\begin{tabular}{|c|c|c|c|c|}
\hline Phase & Number of subjects included & Number of replies & Type of questionnaire & Survey method \\
\hline Screening & $\begin{array}{l}10000 \text { households, i.e. } \\
\text { more than } 20000 \text { adults }\end{array}$ & 15862 adults & Age, sex, weight, height & Self administered, by mail \\
\hline Qualitative interviews & $\begin{array}{l}12 \text { obese subjects: } 6 \text { with } \\
27 \leqslant B M I<30 \text { and } 6 \text { with } \\
B M I \geqslant 30\end{array}$ & $\begin{array}{l}12 \text { obese subjects: } 6 \text { with } \\
27 \leqslant \mathrm{BMI}<30 \text { and } 6 \text { with } \mathrm{BMI} \geqslant 30\end{array}$ & Semidirective & $\begin{array}{l}\text { Administered by a } \\
\text { socio-psychologist }\end{array}$ \\
\hline OSQOL construction and SF36 & 500 obese adults & $\begin{array}{l}\text { 391 obese subjects, including: } \\
\text { - } \mathrm{BMI}<30: 236 \\
-\mathrm{BMI} \geqslant 30: 155\end{array}$ & $\begin{array}{l}32 \text { items classified into } \\
5 \text { headings plus SF36 }\end{array}$ & Self administered, by mail \\
\hline OSQOL construction and SF36 & $\begin{array}{l}500 \text { matched non-obese adults } \\
\text { (sex, age, employment) }\end{array}$ & 462 non-obese subjects & $\begin{array}{l}32 \text { items classified into } \\
5 \text { headings plus SF36 }\end{array}$ & Self administered, by mail \\
\hline
\end{tabular}

four main steps: (1) Initially, a series of semi-directive qualitative interviews was conducted in a small number of obese subjects to define the various complaints concerning quality of life spontaneously expressed by the patients, as well as the terms used. (2) Secondly, a large scale quantitative questionnaire, comprising 32 items classified under five headings, each expressing a "dimension" of quality of life, was constructed. This questionnaire, which exhaustively included all of the themes detected in the previous step, was submitted to a sample of 500 obese subjects and a matched control sample of 500 non-obese subjects. (3) Thirdly, a series of statistical analysis was performed on the answers to the previous questionnaire to eliminate redundancies and to verify the independence of the various dimensions. A scale designed to determine the score for each dimension was also developed. (4) Finally, the usual statistical tests used to assess coherence and reliability were performed on the final instrument.

SELECTION OF THE POPULATION

The study was conducted in a general population derived from the SOFRES permanent survey base. This base consists of approximately 20000 representative "ordinary" households living in mainland France. A self administered questionnaire was sent by mail to one half of the base-that is, 10000 households. This screening questionnaire was intended for adults (over the age of 18 years) and consisted of only four questions concerning age, sex, height, and weight; these last two parameters were used to calculate the body mass index (BMI). (According to the usual formula: $\mathrm{BMI}=$ weight $/$ height $^{2}$ $\left(\mathrm{kg} / \mathrm{m}^{2}\right)$.

For the purposes of this study, the cut off point for obesity was defined as 27 (BMI $\geqslant$ 27 ), corresponding to a conventional definition of this disease. ${ }^{78}$ However, during statistical analysis, a second cut off point of 30 (BMI $\geqslant$ 30) was considered, corresponding to a more restrictive definition of "morbid obesity".

The subsequent surveys were conducted on a series of samples drawn from the population returning the questionnaire: (1) a sample of 12 obese subjects for the qualitative survey in two regions of France; (2) a sample of 500 obese subjects for the quantitative survey leading to construction of the specific scale and for the SF36 scale; (3) a matched sample of 500 nonobese subjects for the same quantitative operations.
To avoid any structural bias, the samples were matched for the three criteria of sex, age, and employment status (employed or unemployed). The employment status was known from the general characteristics of people in the survey base. Therefore, for instance, a 35 year old employed non-obese woman was included in the control population for each 35 year old employed obese woman included in the study population.

Table 1 summarises the population samples, the type of questionnaire, the reply rate, and the survey method.

\section{CONSTRUCTION OF THE QUANTITATIVE}

QUESTIONNAIRE (FIVE DIMENSIONS, 32 ITEMS)

The interviews of the qualitative survey revealed the following five themes (dimensions) that seemed to group the various comments expressed by the subjects concerning their condition: (1) Physical state; (2) agility and suppleness; (3) relations with other people; (4) psychological state; (5) vitality, desire to do things. (The interview guide (six pages) and the list of the main themes of the qualititative studey (45 pages) are available from the authors on request.)

A number of questions (items) were designed for each of these dimensions based on the patients' descriptions. These items were designed in such a way as: (1) to be applicable to all subjects (men, women, young, old, single, married, etc); (2) to implicate the consequences on quality of life.

Comments that remained specific to one group or that expressed only individual preferences (preferences between various types of leisure activity, for example), were not taken into account, although they affected the quality of life of the subject.

The list of 32 items shown in appendix 1 was finally established.

These items consist of declarations for which the subjects had to reply by selecting one of the following five responses: (1) Absolutely true; (2) Fairly true; (3) Neither true nor false; (4) Fairly false; (5) Absolutely false.

These response modalities implied that all items had to be formulated "in the same direction", although the qualitative analysis revealed formulations that were sometimes negative ("People say that I'm not very agile") and sometimes positive ("I am fairly athletic").

The questionnaire resulting from this step was submitted to the group of 500 obese subjects and to the matched control group. 
PROGRESSION FROM THE SEMANTIC SCALE TO THE NUMERICAL SCALE

All of the questionnaires initially received were individually verified to ensure their eligibility, the global coherence of the replies, the compliance with the filters, the completion rate, and to ensure the numerical coding of the replies.

Numerical scores had to be established from qualitative responses to the questionnaire (see appendix 2).

The solution consisting of attributing points (for example, ranging from 1 for absolutely true to 5 to absolutely false) is purely arbitrary, as "absolutely false" does not necessarily have the same weight as "absolutely true".

Therefore, we derive numeric scores for each degree of the scale from a factorial correspondence analysis (FCA), which is a technique well suited to the analysis of contingency tables. ${ }^{9}$ The coordinates on axis 1 of the 5 response modalities were used to quantitatively score each item.

The following scores were finally obtained: Absolutely true:+7.5, Fairly false:-1.0, Fairly true:+3.5, Absolutely false:-4.5, Neither true nor false: +1.0 .

By applying these coefficients to the above two questions, for example, a score of -0.485 was obtained for the first question and a score of -0.075 was obtained for the second question. At this stage, 32 different scores were therefore available for each item of the quantitative questionnaire.

DEVELOPMENT OF THE SPECIFIC SCALE (FOUR DIMENSIONS, 11 ITEMS) FROM THE QUANTITATIVE QUESTIONNAIRE (FIVE DIMENSIONS, 32 ITEMS) The mode of selection of the 32 items of the questionnaire ensured a certain degree of comprehensive information collection, but neither the independence nor the absence of redundancy between the various items. Calculation of a global score on these bases would therefore be biased.

The first operation consisted of testing the independence of the five dimensions and the allocation of the items to these dimensions. Principal component analysis (PCA) with rotation of the axes (Varimax) ${ }^{10}$ was performed on the 32 items.

This analysis revealed that: (1) the 32 items usually appeared to be correlated with one and only one of the first principal factors (only 3 of 32 items had a correlation coefficient greater than $40 \%$ with two different axes); (2) the items indicated in the same dimension were generally correlated with the same factor.

This analysis, however, led to some modifications and reattributions of the items.

The items of the "agility-suppleness" dimension were found to be correlated with the same principal factors as those of the "physical state" dimension. Furthermore, some items belonging to one dimension were found to be more closely correlated with items of another dimension than with those of their original dimension. (For example, the item "I often have moments of exhaustion during the day", initially belonging to the "Physical state"

\section{KEY POINTS}

- A specific quality of life instrument for obesity is developed from a community base large scale sample.

- This instrument shows a gradient of quality of life deterioration between three populations: non-obese, overweight subjects $\quad(27 \leqslant \mathrm{BMI}<30)$, and obese $(\mathrm{BMI} \geqslant 30)$ subjects.

- The generic SF-36 instrument shows quality of life impairment in the obese subjects compared with non-obese only for the five of nine dimensions that are related to physical consequences of obesity.

- This led us to the conclusion that both instruments are complementary in that they did not refer exactly to the same conception of quality of life.

dimension, was actually correlated with the "Vitality, desire to do things" dimension.)

These findings led to: (1) fusion of the "physical state" and "agility-suppleness" dimensions: the final scale therefore consisted of four dimensions: physical state; vitality, desire to do things; relations with other people, mood, psychological state. (2) Reallocation of four items to different dimensions from their original dimension.

The following step consisted of eliminating redundancies between items. Four new Varimax PCA were therefore performed on each of the four independent dimensions established previously. Items correlated with another one were eliminated. This left us with 11 items representing four independent dimensions that constituted the final specific scale.

THE CRUDE SCORE BY DIMENSION

Having reduced the number of items, the task remained of computing the scores by dimension. That is of aggregating the scores of the various items in one dimension into a final score for the dimension itself. The four PCA performed on the dimensions were used for that purpose. The score for a dimension was determined as the average of corresponding items scores, weighted by the mean level of inertia of the factors to which the item significantly contributed. (Only the first four factors were considered. In the "Physical state" dimension, the item " I walk as little as possible" was only correlated with factor 2, which represented $15.72 \%$ of the total inertia of the cloud. The weighting of this item was therefore $15.72 \%$. In contrast, the item "I have trouble squatting" contributed to factors 1,3 , and 4, with levels of inertia of $18.96 \%, 15.42 \%$, and $12.35 \%$, respectively: the weighted coefficient for this item was therefore $15.88 \%$.)

VALIDATION OF THE SCALE

The last step of construction consisted of testing the metrological properties of the instrument constructed during the previous steps.

The content validity, which depends on the way in which an instrument reflects the overall 
Table 2 Structure of the samples

\begin{tabular}{lllll}
\hline & $\begin{array}{l}\text { Non-obese } \\
(n=391)\end{array}$ & $\begin{array}{l}\text { Obese } \\
(n=462)\end{array}$ & $\begin{array}{l}\text { Obese } 27 \leqslant B M I \\
<30(n=236)\end{array}$ & $\begin{array}{l}\text { Obese BMI } \\
\geqslant 30(n=155)\end{array}$ \\
\hline Male & 55 & 58 & 55 & 55 \\
Female & 45 & 42 & 45 & 45 \\
18-25 years & 3 & 4 & 4 & 3 \\
25-35 years & 11 & 13 & 11 & 11 \\
35-49 years & 24 & 25 & 23 & 25 \\
50-64 years & 31 & 31 & 35 & 32 \\
65 years and over & 30 & 27 & 27 & 50 \\
Employed & 50 & 52 & 49 & 50 \\
Unemployed & 50 & 48 & 51 & \\
\hline
\end{tabular}

Table 3 OSQOL items and dimensions

\begin{tabular}{ll}
\hline & Coefficient \\
\hline I have trouble squatting & 15.58 \\
I cannot sit down in a very low armchair & 17.19 \\
I walk as little as possible & 15.72 \\
I have to stop to catch my breath after walking several hundred metres & 16.7 \\
I have trouble climbing stairs & 13.89 \\
People say that I'm not very athletic & 12.35 \\
People often say that I'm not agile & 15.66 \\
Vitality, desire to do things & 49.41 \\
I often lack energy & 25.75 \\
I don't move around very much & 23.9 \\
Relations with other people & \\
I feel I'm being attacked when people talk about my corpulence & 42.15 \\
Psychological state & \\
I feel very ill at ease & \\
\hline
\end{tabular}

situation that it is supposed to assess, was ensured by the mode of selection of the items derived from the detailed qualitative interviews.

The construct validity - that is, the capacity of the scale to accurately assess the pathological state-was ensured by means of two tests using external references:

A score monotony test

A series of subsamples of obese and non-obese subjects was drawn to confirm the existence of a monotonic positive relation between the number of positive replies in the subsample and the score calculated for this item.

\section{A specificity test}

The correlation between the score and the clinical state, in this case the BMI, was determined by verifying that a positive correlation was obtained without being excessively high, as quality of life is not simply the expression of the BMI.

Finally, the reliability of the scale was tested by using the classic $\alpha$ test of Cronbach, ${ }^{11}$ which measures the relative degree of covariance between items in the total variance of the observations and which ensures that the various items are coherent between each other without being redundant.

THE SF36 SCALE

In parallel with construction of the specific scale, the generic SF36 quality of life scale, developed by John Ware, ${ }^{12}$ was also applied to the same samples.

This scale was selected because of : (1) its simplicity: 36 items grouped into 11 questions of a self administered questionnaire. (2) Its scientific recognition, as this scale is very widely used in clinical research and has been extensively validated in very different populations. (3) Its availability in French, as a validated translation has been established.
The SF 36, which is not described in detail here, is used to determine quantitative scores for nine dimensions: physical activity (physical functioning), activity limitations because of physical state (physical role), physical pain (bodily pain), perceived health (general health), vitality, social life (social functioning), limitations because of psychological state (emotional role), mental health, course of perceived health (reported health transition).

\section{Results}

STUDY POPULATION

A total of 8132 of 10000 contacted households of the SOFRES base returned the questionnaire, which corresponds to a population of 15862 people over the age of 18 years. The prevalence of obesity, defined by a BMI greater than or equal to 27 , was $18 \%$, but was only $6 \%$ according to the more restrictive definition of a BMI greater than or equal to 30 .

Comparison of the structure of the obese population in terms of the criteria of sex, age, and employment showed (table 2): (1) an overrepresentation of men compared with the nonobese population $(57 \%$ versus $45 \%$, $\mathrm{p}=0.0410)$; (2) an underrepresentation of the youngest age group, $18-35$ years $(39 \%$ versus $48 \%, \mathrm{p}=0.0013)$; (3) an underrepresentation of employed subjects $(53 \%$ versus $58 \%$, $\mathrm{p}=0.4049$ ).

Matching of the obese and non-obese samples and the correction performed on the sample of obese subjects with a BMI $\geqslant 30$ eliminated these structural differences.

A total of 873 of 1000 questionnaires sent to the two samples were returned. Twenty questionnaires were excluded from the analysis, 16 because they had not been completed by the right person and four because they presented an insufficient completion rate. The analysis was therefore based on 853 subjects.

The screening phase and dispatch of the questionnaires were separated by a long interval (nine month): 55 people who were obese during the screening phase were no longer obese during the survey phase; conversely 15 people who were not obese during the screening phase had become obese during the survey phase. These people were reintegrated into their appropriate new groups.

The final results are therefore based on: 462 non-obese subjects; 391 obese subjects, including $27 \leqslant \mathrm{BMI}<30: 236(60 \%), 30 \leqslant \mathrm{BMI}$ : $155(40 \%)$.

\section{THE SPECIFIC SCALE}

Based on the approach described in the previous section, a specific quality of life scale for obesity was able to be proposed, comprising 11 items classified into four dimensions (table 3 ).

Five response modalities are available for each item (ranging from "absolutely true" to "absolutely false"). Table 4 reports the crude score for each dimension computed using the method described above.

The statistical tests verified that: (1) All items confirmed the monotonic relation described previously. (2) The specificity test gave a correlation coefficient of 0.40 , meaning that 
Table 4 OSQOL scores and dimension

\begin{tabular}{|c|c|c|c|}
\hline & $\begin{array}{l}\text { Non-obese } B M I \leqslant 27 \\
(n=462)\end{array}$ & $\begin{array}{l}\text { Obese } 27 \leqslant B M I<30 \\
(n=236)\end{array}$ & $\begin{array}{l}\text { Obese } B M I \geqslant 30 \\
(n=155)\end{array}$ \\
\hline Physical state & $71.6(19.0)$ & $64.1(20.3)^{\star \star \star}$ & $57.2(20.3)^{\star \star \star}+十 \dagger$ \\
\hline Vitality, desire to do things & $64.1(17.0)$ & $60.4(22.7)^{\star}$ & $55.6(22.7)^{\star \star \star} \dagger$ \\
\hline Relations with other people & $69.4(18.4)$ & $67.8(20.6)$ & $66.3(20.6)$ \\
\hline Psychological state & $66.5(18.7)$ & $64.4(19.2)$ & $61.2(19.2)^{\star \star}$ \\
\hline
\end{tabular}

Data shown as mean (SD). ${ }^{\star} \mathrm{p}<0.05,{ }^{\star \star} \mathrm{p}<0.01,{ }^{\star \star \star} \mathrm{p}<0.001$ compared with the non obese group. $\dagger \mathrm{p}<0.05, \ddagger \neq \mathrm{p}<0.01, \ddagger \ddagger \neq \mathrm{p}<0.001$ compared with overweight subjects.

Table 5 SF36 scores

\begin{tabular}{llll}
\hline & $\begin{array}{l}\text { A Non-obese } \\
(n=562)\end{array}$ & $\begin{array}{l}\text { B Obese 27 } \\
(n=236)\end{array}$ & $\begin{array}{l}\text { C ObeseBMI } \\
(n=155)\end{array}$ \\
\hline Physical functioning & $83.7(21)$ & $79.5(12)^{\star}$ & $74.6(21)^{\star \star \star}$ \\
Physical role & $80.3(31)$ & $81.7(32)$ & $73.0(35)^{\star}+\dagger$ \\
Bodily pain & $69.6(14)$ & $69.3(27)$ & $64.5(29)^{\star}$ \\
General health & $66.4(19)$ & $65.9(18)$ & $62.2(17)^{\star}$ \\
Vitality & $57.6(19)$ & $57.6(14)$ & $53.2(16)^{\star \star}$ \\
Social functioning & $79.0(31)$ & $80.2(21)$ & $77.1(12)$ \\
Emotional role & $81.6(32)$ & $81.0(35)$ & $76.2(35)$ \\
Mental health & $66.5(16)$ & $66.8(19)$ & $57.8(17)$ \\
Reported health transition & $50.5(15)$ & $49.5(14)$ & $52.4(13)$ \\
\hline
\end{tabular}

Data shown as mean (SD). ${ }^{\star} \mathrm{p}<0.05,{ }^{\star \star} \mathrm{p}<0.01,{ }^{\star \star \star} \mathrm{p}<0.001$ compared with the non-obese group. $\mathrm{tp}<0.05,+\dagger \mathrm{p}<0.01,+\dagger+\mathrm{p}<0.001$ compared with overweight subjects.

the quality of life, while being correlated with the BMI, represents nevertheless an independent dimension of the pathology. (3) Cronbach's coefficient $\alpha$ of the scale was 0.77 , higher than the usual lower threshold for reliability (0.65).

SCORES ON THE GENERIC SCALE (SF36)

Table 5 shows the results obtained with the SF36 scale.

\section{Discussion}

We developed a quality of life instrument in obesity, the OSQOL, and compared the results with a generic instrument, the SF-36.

The OSQOL differs from that already been published $^{3413}$ in various aspects: (1) the use of a community based large scale sample; (2) the use of a control group; (3) the reduction of the size of the scale to a small number of items.

By contrast the IWQOL scale (74 items) was constructed from interviews of a small sample of subjects (64) in treatment for obesity. ${ }^{3}$

Both the generic and the specific scales indicated a change in the quality of life in the obese subjects group compared with the non-obese group.

Analysis of the SF36 quality of life scores suggests the following comments: (1) The group of moderately obese subjects did not differ from the control group except for physical capacity; (2) In the group of obese subjects with a BMI greater than or equal to 30 , quality of life seemed to be impaired for five of nine dimensions compared with the control population, all related to physical consequences of obesity: "Physical functioning", "physical role", "bodily pain", "general health", and "vitality". This population essentially perceived itself in terms of poor general health. (2) No significant difference was observed between the three samples for the psychological and social dimensions of quality of life.

In summary, the generic SF 36 scale defines a cleavage between obese subjects with a BMI greater than or equal to 30 and all other subjects. The physical and somatic aspects were impaired by obesity rather than the psychological and social aspects, for which no significant difference was observed. In contrast, the specific scale revealed significant differences for each of its dimensions and showed a gradient of deterioration of quality of life between the three populations.

These results are not surprising, as the scale was specifically designed to show them. They should be considered as a test of the capacity of the scale to discriminate between populations with different BMI.

What should be noticed is the number of items related to physical performances (nine of 11). They express, much more precisely than the generic scale does, the dimensions of the physical consequences of obesity: suppleness, physical capacity, self limitation of physical performances, feeling of lack of vitality, and dynamism.

In this study we find that the quality of life of patients with severe obesity is impaired, but it mainly affects the physical consequences of the disease. The psychological and social repercussions that could have been expected to affect this population were not demonstrated. The hypothesis of a process of adaptation of a person to their social environment cannot therefore be excluded.

These results confirm those reported by other authors. For example, Gortmaker et $a l^{4}$ did not observe any significant reduction of self esteem in a population of young obese subjects despite lower levels of education, marriage, and income.

The OSQOL and IWQOL, ${ }^{3}$ although they were developed in a similar way, differ in the number of items (11 compared with 74). The two scale share common topics: physical state mobility, social activity. The IWQO1 includes other dimensions that are not present in the OSQOL: work, self esteem, sexual life, comfort with food. As stressed by Kolotkin ${ }^{3}$ some items of the IWQOL are questionable and should be probably deleted (comfort with food).

Comparison of the specific OSQOL with the generic SF36 shows clearly that they correspond to different objectives. The generic scale is designed to be a reference instrument allowing a disease to be situated in relation to all other diseases. It can be used to compare obesity and its consequences with other chronic diseases, for example osteoarthritis of the knee, which was also studied from the dual perspective of a generic instrument and a specific instrument. ${ }^{14} 15$

The specific scale has a more limited objective: in view of its characteristics, it can only be used to measure differences of quality of life within the obese population, either to evaluate the effect of treatment or to measure the degree of severity of the disease.

However, these two instruments can be complementary. Firstly, the simultaneous use of the two instruments tends to reinforce the conclusions that can be drawn from each scale considered separately.

For example, two hypotheses can be proposed to explain the absence of psychological and social phenomena demonstrated by the SF36-either the real absence of this type of 
repercussion or the lack of sensitivity of the measuring instrument. The results of the specific scale are in favour of the first hypothesis: an ad hoc scale, constructed in such a way as to emphasise differences, also fails to attribute a great importance to these types of consequences compared with physical repercussions.

Secondly, these two scales are also complementary in that they do not provide exactly the same perception of the quality of life.

On the one hand, the quality of life assessed by the generic scale refers to a universal and normative concept of the good physical, mental, and social functioning. On the other hand, the specific instrument is based on real situations experienced by the patients and strives to achieve a more organised, more compact conception of quality of life, by emphasising the elements that discriminate this population from a control population.

Funding: this research was supported by a grant from ARDIX MEDICAL, Paris, France.

\section{Appendix 1}

List of the initial 32 items of the specific scale

\section{Physical state}

- 50/1 People say that I am athletic

- 50/2 I don't hesitate to run to catch a bus

- 50/3 I don't move around very much

- 52/1 Even going downstairs is difficult for me

- $52 / 2$ When I climb the stairs, I have to rest to catch my breath after several steps

- 52/3 I have trouble climbing stairs

- 61/1 I can go for long walks without any problems

- $61 / 2$ I tend to walk slowly

- $61 / 3$ I walk as little as possible

- 61/4 I have to stop to catch my breath after walking several hundred metres

- 64/3 I tire rapidly when vacuum cleaning

- 64/4 I often have trouble carrying heavy objects

- 5/? I often have moments of exhaustion during the day

- 55/? I feel that my physical functioning slowed

Agility, suppleness

- 51/1 People often say that I'm agile

- 51/2 I have trouble squatting

- 51/3 I have trouble kneeling

- 51/5 I cannot sit down in a very low or very deep armchair

- 59/4 I have trouble getting on and off buses, trains, subway, etc

- 64/1 I have trouble standing on a stepladder or climbing a ladder
- 64/2 I don't have any trouble bending down

Relations with other people

- 33/1 I feel that people easily confide in me

- 33/2 I have trouble relating to other people

- 33/3 I feel that everyone is watching me when I enter a room

- 53/4 I easily make contact with new people

- 53/6 I feel I'm being attacked with people talk about my corpulence

Vitality, desire to do things

- 55/1 I often lack energy

- 55/3 I'm not easily discouraged

\section{Psychological state}

Appendix 2

\begin{tabular}{lll} 
& $\begin{array}{l}\text { I find it difficult } \\
\text { to relate to other } \\
\text { people }\end{array}$ & $\begin{array}{l}\text { In summer, I hesitate } \\
\text { about wearing a } \\
\text { swimsuit }\end{array}$ \\
\hline Absolutely true & $3 \%$ & $11 \%$ \\
Fairly true & $17 \%$ & $17 \%$ \\
$\begin{array}{l}\text { Neither true nor false } \\
\text { Fairly false }\end{array}$ & $22 \%$ & $19 \%$ \\
Absolutely false & $31 \%$ & $20 \%$ \\
& $27 \%$ & $33 \%$
\end{tabular}

- 55/2 I'm easily irritated

- 55/4 I'm generally in a good mood

- 55/ 5 I feel very much at ease

1 Wolf AM, Colditz GA. The cost of obesity: the US perspective. Pharmacoeconomics 1994;5 (suppl 1):34-7.

2 Gorstein J, Grosse R. The indirect cost of obesity to society. Pharmacoeconomics 1994;5 (suppl 1):58-61.

3 Kolotkin RV, Head S, Hamilton M, et al. Assessing impact of weight on quality of life. Obes Res 1995;3:49-56.

4 Gortmaker SL, Must A, Perrin JM, et al. Social and Gortmaker SL, Must A, Perrin JM, et al. Social and economic consequences of overweight in adolescence

5 Jaeschye R, Guyatt GH. How to develop and validate a new quality of life instrument. In: Spilker B, ed. Quality of life assessments in clinical trials. New York: Raven Press, 1990:47-50.

6 Patrick DL, Erickson P. Assessing health-related quality of life for clinical decision-making. In: Walker SR, Rosser RM,eds. Quality of life assessment, key issues in the 1990s. Dordrecht: Kluwer Academic, 1992:11-63.

7 Burton B, Foster WR. Health implications of obesity: an HIH consensus development conference. 7 Am Diet Assoc 1985;85:1117-21

8 Rolland Cachera MF, Cole TJ, Sempe M, et al. Variations of the body mass index in the French population from 0 to 87 vears. In: Ailhaud G, Guy-Grand B, Lafontan M, at years. In: Ailhaud G, Guy-Grand B, Lafontan M, et al, eds. Obesity in Europe Paris: John Libbey, 1991:113-20.

9 Greenacre MJ. Theory and applications of correspondance analysis. London: Academic Press, 1984.

10 Morisson DF. Multivariate statistical methods. New York: McGraw-Hill, 1976.

11 Cronbach LJ. Coefficient alpha and the internal structure of test. Psychmetrika 1951;16:297.

12 Ware JE, Shelbourne CD. The MOS 36 item Short Form Health Survey (SF 36): I. Conceptual framework and item selection. Med Care 1992;30:473-83.

13 Sullivan MBE, Sullivan LGM, Kral JG. Quality of life assessment in obesity: physical, psychological and social function. Gastroenterol Clin North Am 1987;16:433-42.

14 Hawker GA, Melfi CA, Paul JE, et al. Comparison of a generic (SF 36) and a disease-specific (WOMAC) instrument in the measurement of outcomes after knee replacement surgery. I Rheumatol. 1995;22:1193-6.

15 Patrick DL, Deyo RA. Generic and disease-specific measures in assessing health status and quality of life. Med Care 1989; 27 (suppl):5217-32. 